\title{
Cystic Breast Cancer. A Confusing Entity. Study of 8 Cases at Dakar University Surgical Oncology Unit
}

\author{
Sidy Ka, Mamour Gueye, Mamadou M. Dieng, Salif Baldé, Samuel Kobinama, Jaafar Thiam, \\ Ahmadou Dem
}

Centre Hospitalier Universitaire Le Dantec, Dakar, Sénégal

Email: kasidyoasis@gmail.com

How to cite this paper: Ka, S., Gueye, M., Dieng, M.M., Baldé, S., Kobinama, S., Thiam, J. and Dem, A. (2022) Cystic Breast Cancer. A Confusing Entity. Study of 8 Cases at Dakar University Surgical Oncology Unit. Advances in Breast Cancer Research, 11, 69-74. https://doi.org/10.4236/abcr.2022.111005

Received: January 5, 2022

Accepted: January 26, 2022

Published: January 29, 2022

Copyright $\odot 2022$ by author(s) and Scientific Research Publishing Inc. This work is licensed under the Creative Commons Attribution International License (CC BY 4.0).

http://creativecommons.org/licenses/by/4.0/

\section{(c) (i) Open Access}

\begin{abstract}
Introduction: Cystic breast cancer is a rare entity. Breast cysts are most often benign. The clinical characteristics of malignancy are not specific. Objective: To report a series of malignant cystic tumors of the breast and to describe their different characteristics. Materials and Methods: This was an observational study carried out between January 2018 and October 2021 at the Dakar university surgical oncology unit. We studied the clinical appearance, imaging, histopathology, extent of disease and treatment. We did not include cases of pure, single, or multiple chronically progressive cysts. Results: There were 8 patients, 6 women and 2 men. The average age was 44 . All patients presented with a palpable unilateral deforming skin mass without inflammatory character. One patient presented with a bloody discharge. The cyst was multilocular without intracystic growth in 2 cases and presented a growth signal in 6 cases. Imaging was ACR 3 in 5 cases and ACR 4 in 3 cases. Histopathology found 6 invasive carcinomas including 2 papillary, 3 Invasive Carcinoma of No Special Type (ICNST), 1 lobular carcinoma as well as one case of lobular carcinoma in situ of the comedocarcinoma type in women and 2 ICNST in men. The extension workup was found in only 1 male patient in the presence of metastases. Treatment included chemotherapy, mastectomy and radiotherapy for 6 of the patients. There wasn't any complete response for invasive cases. Survival is 100\% to date. Conclusion: Cystic breast tumors sometimes hide the cancer that is difficult to diagnose. The prognosis seems favorable, however.
\end{abstract}

\section{Keywords}

Breast, Cyst, Carcinoma 


\section{Introduction}

The discovery of a lump in the breast leads to fear of cancer. Intracystic breast cancer accounts for $0.5 \%-2 \%$ of breast cancers. And in complex breast cysts, an underlying cancer is present in $21 \%-31 \%$ of cases [1].

Medical imaging can characterize the presence of cystic tumors [2]. They are most often benign. The clinical characteristics of malignancy are not specific [3]. The objective is to report a series of malignant cystic breast tumors and to describe their clinical and therapeutic characteristics.

\section{Materials and Methods}

This is an observational study carried out between January 2018 and October 2021 at the university unit of oncological surgery in Dakar. We studied the clinical appearance, imaging, histopathology, clinical stage and response to treatment of cases of suspicious cystic tumours. We did not include cases of pure, single or multiple ACR breast cysts. The patients were chosen by the team in the event of a suspicious cyst on imaging. And follow-up was done by a single team member until treatment.

\section{Results}

There were 8 patients, 4 women and 2 men. The average age was 44 . All patients presented with a palpable unilateral skin deforming mass without inflammatory character (Figure 1 and Figure 2). One patient presented with a bloody discharge. The cyst was multilocular without intracystic growth in 2 cases and presented cystic growth in 6 cases. Imaging was ACR 3 in 5 cases and ACR 4 in 3 cases. Ultrasound, especially associated with Doppler, was an important contribution to the diagnosis (Figure 3). Needle biopsy was not immediately feasible in 6 patients. Ultrasound-guided cytology helped guide the diagnosis in these 6 cases (Figure 3). A biopsy under ultrasound directed towards the tissue part and bypassing the superficial parts made it possible to make the histological diagnosis (Figure 4).

Histopathology found 2 ICNST, 2 papillary carcinomas, 1 invasive lobular carcinoma, 1 in situ lobular carcinoma with comedo necrosis in women and 2 ICNTS in men (Table 1).

The extension workup found in only 1 male patient the presence of pulmonary metastases. All the patients were classified stage 2 and 3 with 1 case of stage

Table 1. Histological distribution of cystic tumors.

\begin{tabular}{ccc}
\hline Type histologique & Number & $\%$ \\
\hline ICNST & 4 & 50 \\
Papillairy carcinoma & 2 & 25 \\
ILC & 1 & 12,5 \\
ISLC & 1 & 12,5
\end{tabular}




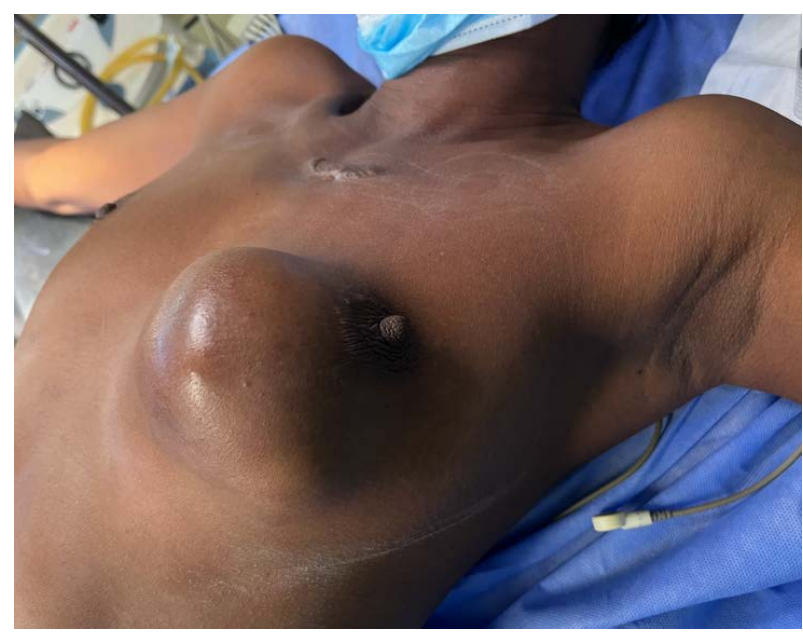

Figure 1. Large breast mass without skin involvement.

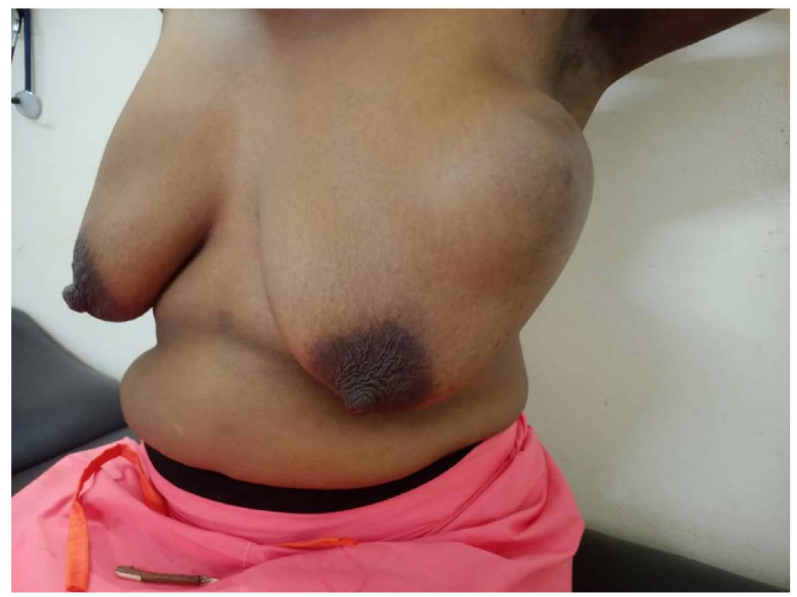

Figure 2. Case of a big breast cyst in woman.

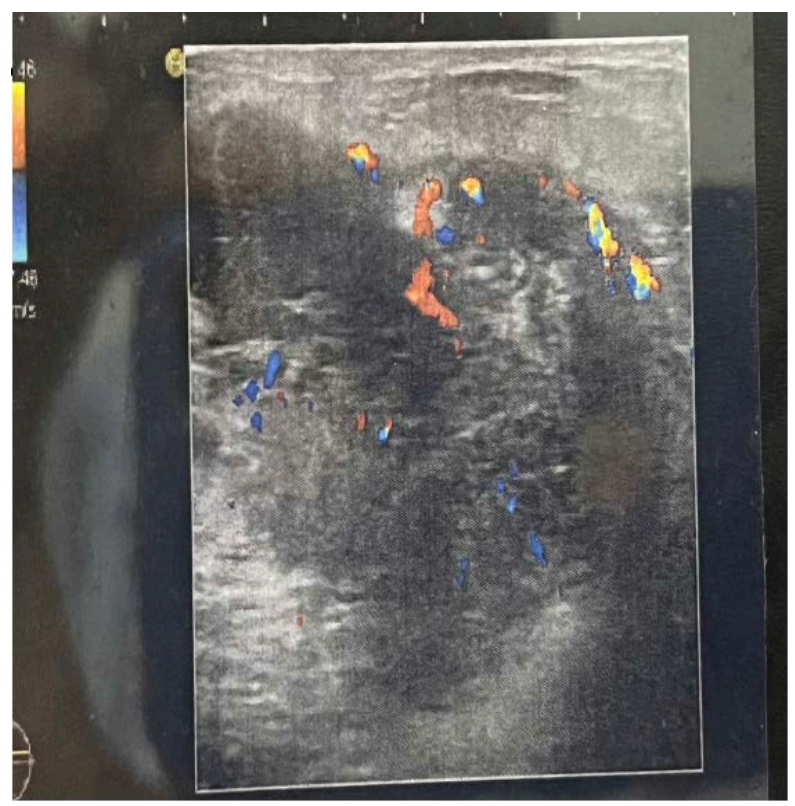

Figure 3. Doppler ultrasound of an intracystic growth of the breast. 
4. The treatment included chemotherapy for all the patients followed by mastectomy then radiotherapy for 6 patients. We performed mastectomy for the man who did not present metastasis (Figure 5). To this day they are all alive.

\section{Discussion}

Breast cysts are a common and generally thought to be benign entity. Intracystic cancers represent less than $2 \%$ of breast cancers [1]. They are found in women and men in whom they do not represent an exceptional entity relative to women [4]. Usual age is advanced and over 60 years old. In our context, the age of patients followed for breast cancer is usually 10 - 15 years younger [5].

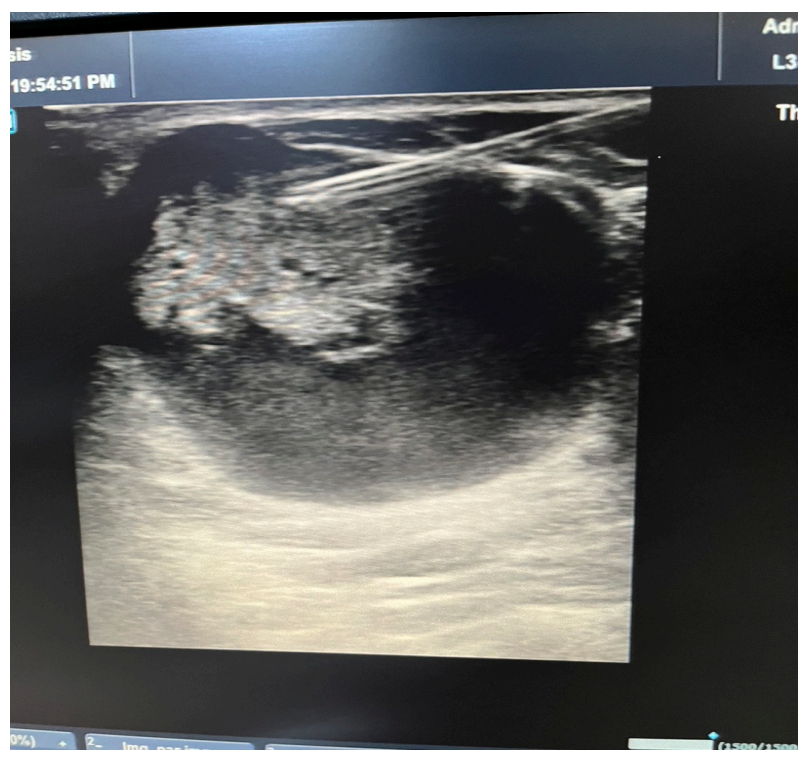

Figure 4. Ultrasound-guided puncture of intracystic growth.

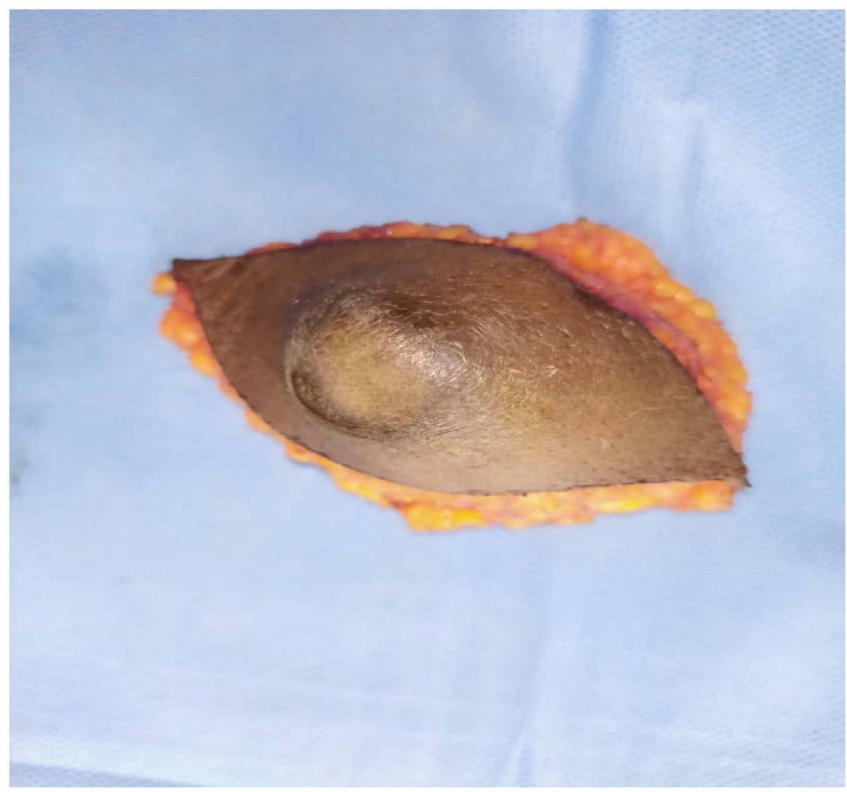

Figure 5. Surgical specimen of breast cyst surgery on man. 
Screening tests help find and monitor common breast cysts. The feeling of a lump is the most common sign. The rate of increase in mass is also a frequent diagnostic feature [1]. The proportion of discharge is also more common than in solid cancers. Inflammatory cancer is rarer. These proportions are found in our patients despite the short series.

The ultrasound shows the fluid nature of the mass. New imaging modalities like Quantitative Transmission (QT) Ultrasound and Doppler modalities allow better characterization of cysts.

Mammography, ultrasound and MRI show the cystic and growth parts. The suspicion of malignancy is on the extent and vascularization of the growth, apart from classic basic lesions such as calcifications [6].

It may be difficult to classify the lesion on imaging. Hence the necessary caution in the event of a large cyst or a mixed cyst [7]. Complex cysts are defined by mixed growth and fluid content. They are classified ACR 4 . However, they are more frequently benign than malignant [8]. In the case of malignancies, these are mainly papillary, necrotic, in situ or metastatic cancers. Papillary carcinomas are more common than in lumpy cancers. Intra-cystic papillary carcinoma of the breast is a very rare entity and represents $0.5 \%$ to $1 \%$ of all mammary carcinomas. The association with comedo necrosis and calcifications is common especially in cases of carcinoma in situ or in cases of invasive carcinoma with necrosis simulating comedo necrosis [9].

The clinical appearance of cysts does not allow determining their benign or malignant characters. On the other hand, metastases to the breast can be cystic. Metastases from breast cancer to other organs can also be cystic. There is no evidence that there is a relationship between the cystic appearance of the primary and the appearance of metastasis. At equal size, cystic cancer appears to be less frequently metastatic [10].

Treatment depends on the stage. The often large tumor size corresponding to T3 requires in invasive cancers, neoadjuvant chemotherapy followed by surgery and radiotherapy. Conservative surgery is more rarely performed due to the size of the mass [11]. If associated with suspicious discharge, pyramidectomy may be the preferred surgical solution [12].

The prognosis for cystic breast cancers is favorable compared to the prognosis of solid cancers [1] [11] [13].

\section{Conclusion}

Cystic breast tumors sometimes hide the cancer that is difficult to diagnose. Cytology is used to evoke the diagnosis. The biopsy must be rigorous. it requires tricks and a trained practitioner. intracystic papillary carcinoma is the most common type. The prognosis seems favorable, however.

\section{Conflicts of Interest}

The authors declare no conflicts of interest regarding the publication of this paper. 


\section{References}

[1] Salemis, N.S. (2018) Intracystic Breast Carcinoma. An Important Differential Diagnosis in Postmenopausal Patients Presenting with a Rapidly Growing Breast Cyst. Management and Literature Review. Breast Disease, 37, 219-224. https://doi.org/10.3233/BD-170316

[2] Iuanow, E., Smith, K., Obuchowski, N.A., Bullen, J. and Klock, J.C. (2017) Accuracy of Cyst versus Solid Diagnosis in the Breast Using Quantitative Transmission (QT) Ultrasound. Academic Radiology, 24, 1148-1153. https://doi.org/10.1016/j.acra.2017.03.024

[3] Athanasiou, A., Aubert, E., Salomon, A.V. and Tardivon, A. (2014) Masses kystiques complexes en échographie mammaire. Journal de Radiologie Diagnostique et Interventionnelle, 95, 175-185. https://doi.org/10.1016/j.jradio.2013.12.008

[4] Kihara, M., Mori, N., Yamauchi, A. and Yokomise, H. (2004) A Case of Intracystic Papillary Carcinoma with a Multilocular Cyst of the Breast in Male. Breast Cancer, 11, 409-412. https://doi.org/10.1007/BF02968050

[5] Sidy, K., Mohamed, E.C., Jaafar, T., Adja, C.D., Papa, S.D., et al. (2020) Post-Mastectomy Lymphocele after Breast Cancer Surgery: Risk Factors Evaluation. Cancer Therapy \& Oncology International Journal, 17, Article ID: 555957. https://doi.org/10.19080/CTOIJ.2020.17.555957

[6] Catalano, O., Raso, M.M., D’Aiuto, M., Illiano, L.A., Saturnino, P.P. and Siani, A. (2009) Additional Role of Colour Doppler Ultrasound Imaging in Intracystic Breast Tumours. La Radiologia Medica, 114, 253-266. https://doi.org/10.1007/s11547-008-0346-6

[7] Kihara, M. and Miyauchi, A. (2010) Intracystic Papilloma of the Breast Forming a Giant Cyst. Breast Cancer, 17, 68-70. https://doi.org/10.1007/s12282-008-0092-6

[8] Ohlinger, R., Frese, H., Schwesinger, G., Schimming, A. and Köhler, G. (2005) Papillary Intracystic Carcinoma of the Female Breast-Role of Ultrasonography. Ultraschall in der Medizin, 26, 325-328. https://doi.org/10.1055/s-2004-813427

[9] Go, E.M., Chan, S.K., Vong, J.S., Lui, P.C., Chan, A.W., Ma, T.K., Ang, M.A., Law, B.K., Tan, P.H. and Tse, G.M. (2010) Predictors of Invasion in Needle Core Biopsies of the Breast with Ductal Carcinoma In Situ. Modern Pathology, 23, 737-742. https://doi.org/10.1038/modpathol.2009.187

[10] Tao, Y., Yagi, K., Nishimura, H., Hara, K., Matsubara, S. and Uno, M. (2019) Orbitotemporal Bone Cyst of Metastatic Breast Cancer: Case Report and Literature Review. World Neurosurgery, 130, 267-270. https://doi.org/10.1016/j.wneu.2019.07.076

[11] Kitada, M., Hayashi, S., Matsuda, Y., Sato, K., Miyokawa, N. and Sasajima, T. (2011) Surgical Treatment of Intracystic Carcinoma of the Breast. World Journal of Surgical Oncology, 9, Article No. 116. https://doi.org/10.1186/1477-7819-9-116

[12] Ka, S., Some, R., Thiam, J., Dieng, M.M., Diouf, D., Gaye, P.M. and Dem, A. (2018) La pyramidectomie dans l'écoulement mamelonnaire pathologique à l'Institut Joliot Curie de Dakar. Journal de la $S A G O, 19,1-4$.

[13] Dhebri, A.R., Ahmad, A., Shah, N. and Arora, P.K. (2012) Intracystic Papillary Carcinoma of Breast: Report of Three Cases and Review of the Literature. BMJ Case Reports, 2012, Article No. bcr2012007237. 